\title{
Research on Reform and Practice of School- Enterprise Integration Talent Cultivation Model of Cuisine Specialty in Guangxi Secondary Vocational Schools
}

\author{
Xin Xie ${ }^{1}$ Guanqiang Liang ${ }^{1}$ Biyue Long ${ }^{1, *}$ \\ ${ }^{1}$ Guangxi Business School, Guilin, Guangxi, China \\ *Corresponding author. Email: 25936436@qq.com
}

\begin{abstract}
With the promotion of "the Belt and Road Initiative", Guangxi's catering industry is showing a vigorous growth momentum. The development of Guangxi's catering companies tends to be diversified and their scales are gradually expanding. Companies need technical support from experienced and resourceful masters. At the same time, the demand for employees in the catering industry presents a trend of echelon. The catering industry not only values the professional skills of employees, but also pays attention to the comprehensive abilities, such as creativity, innovation and communication. Against this background, this paper focuses on the reform and innovation of talent training mode for students majoring in cuisine in vocational schools. The talent training mode of "school-enterprise integration and increased enrolment and fade-out" is creatively put forwarded. Also, this paper carries out the investigation on the implementation of this mode in the past five years. Under this mode, the "integrated" course system, the project "one county and one brand" and the practice mode of "increased enrolment and fade-out, and alternation of working and learning" can effectively improve students' professional quality and vocational skills. At the same time, this mode can effectively solve the practical difficulties of enterprises and promote local enterprises to inherit local food culture by exerting the resources of "masters".
\end{abstract}

Keywords: Integration of industry and education, Increased enrolment and fade-out, Integrated curriculum, One county and one brand, The improvement of professional skills.

\section{INTRODUCTION}

The "Decision of the State Council on Vigorously Promoting the Reform and Development of Vocational Education" states that "the cultivation of skilled workers, especially senior skilled workers and technicians, should be vigorously strengthened [1]. And it is required to actively promote curriculum reform and teaching material reform." With the promotion of "the Belt and Road Initiative", the catering industry in Guangxi presents a strong momentum of growth. With the continuous adjustment of market structure, the development of catering enterprises in Guangxi tends to be diversified and the scale is gradually expanding [2]. The demand for employees presents a trend of ladder. The catering industry in Guangxi not only values the professional skills of employees, but also focuses on the comprehensive abilities, such as creativity, innovation and communication 6[]. Guangxi Business School has implemented the first-level project of education reform and research in autonomous region "Construction and Research of "Golden BlueCollar" Talent Training Curriculum System for Cuisine Major in Secondary Vocational Schools", second-level project — "Taking Work Process as the Orientation and Professional Competence as the core, Making Construction and Research of Chinese Cooking and Nutritional Catering Curriculum System in Secondary Vocational Schools", and "Construction and Research of Integrated Teaching Curriculum System of Western Cuisine Specialty in Secondary Vocational 
Schools", etc [5]. Relying on National Master Studio (Xie Xin), it carries out in-depth research and promotion and constantly makes the refining and innovation in teaching reform and practice. With the help of the national skilled masters in this teaching team, "National Model Teacher", and "ten thousand of teaching masters", schools and enterprises participate in talent cultivation. Led by Yang Mingduo, a famous national vocational teacher, and more than 10 Chinese culinary masters such as Xie Xin, Liang Guanqiang, Liu Yangming and Duan Wenqing, the talent training mode of "school-enterprise-industry co-cooperation, increased enrolment and fade-out" was formed in 2015 through exploration and practice. After nearly 5 years of research and promotion, the talent training mode has achieved fruitful results.

\section{THE MAIN TEACHING PROBLEMS SOLVED BY THE RESULTS}

First, the students' comprehensive professional abilities are weak, which cannot meet the multilevel needs of enterprises for talents;

Second, the problem of inaccurate connection between students' professional skills and corporate positions;

Third, in the process of cultivating talents by school and enterprise, the single way of enterprise participation is not conducive to talent training.

\section{IDEAS FOR THE FORMATION OF RESULTS}

In order to improve the quality of talent training, the teaching team started from the problem, solved and advanced step by step, and took the Chinese cuisine major as the opportunity for the key construction of the national reform and development model school (started in April 2013), and strived to explore new ideas and new models of talent training.

In the concept, it proposes the innovative construction of talent training mode of "schoolenterprise-industry co-cooperation, increased enrolment and fade-out". Based on the platform advantage of "Master Studio", it is to connect enterprises and industries. The talent training mode of "school-enterprise-industry co-cooperation, increased enrolment and fade-out" has been led by national famous vocational teachers, with the coconstruction of schools, enterprises and industries as the basis and students as the main body. It is necessary to give full play to the main role of school-enterprise-industry co-cooperation in educating people, and a win-win-win situation of "co-cultivation of talents", "co-management of processes" and "sharing of achievements" is formed. The strategy of "increased enrolment and fade-out" has promoted the integration of industry and education, and the "multi-post rotation" has promoted the alternation of working and learning. As the results are practiced, the education and teaching theory of school-enterprise integration can be expanded, promoting the deep cooperation between schools and enterprises and close integration of working and learning.

Developing an "integrated" curriculum system of "school-enterprise-industry docking" It is required to start from solving the contradiction between talent supply and demand of catering industry, follow the steps of industrial transformation and upgrading, and take the comprehensive vocational ability as the core. Led by the masters, the "school-enterprise-industry docking" is established, such as the docking between the curriculum setting of cuisine specialty and enterprise demand, the docking between course content and professional standards, and the docking between course teaching and production process. Then, talents and technical positions of enterprises are matched accurately. Through vigorously promoting the integrated teaching mode of "teaching in doing and learning in doing", the teaching quality has been significantly improved to achieve the three educational goals of "professional quality, professional skills and comprehensive ability".

Through the implementation of the project "one county and one brand", it can help the enterprise to establish a brand image, enhance the brand connotation, accelerate the development of enterprises, improve the strength, and enhance the social service ability. A three-party community of mutual benefit and multiplier of interests and a new model of deep cooperation between schools and enterprises have been established. ("Figure 1") 


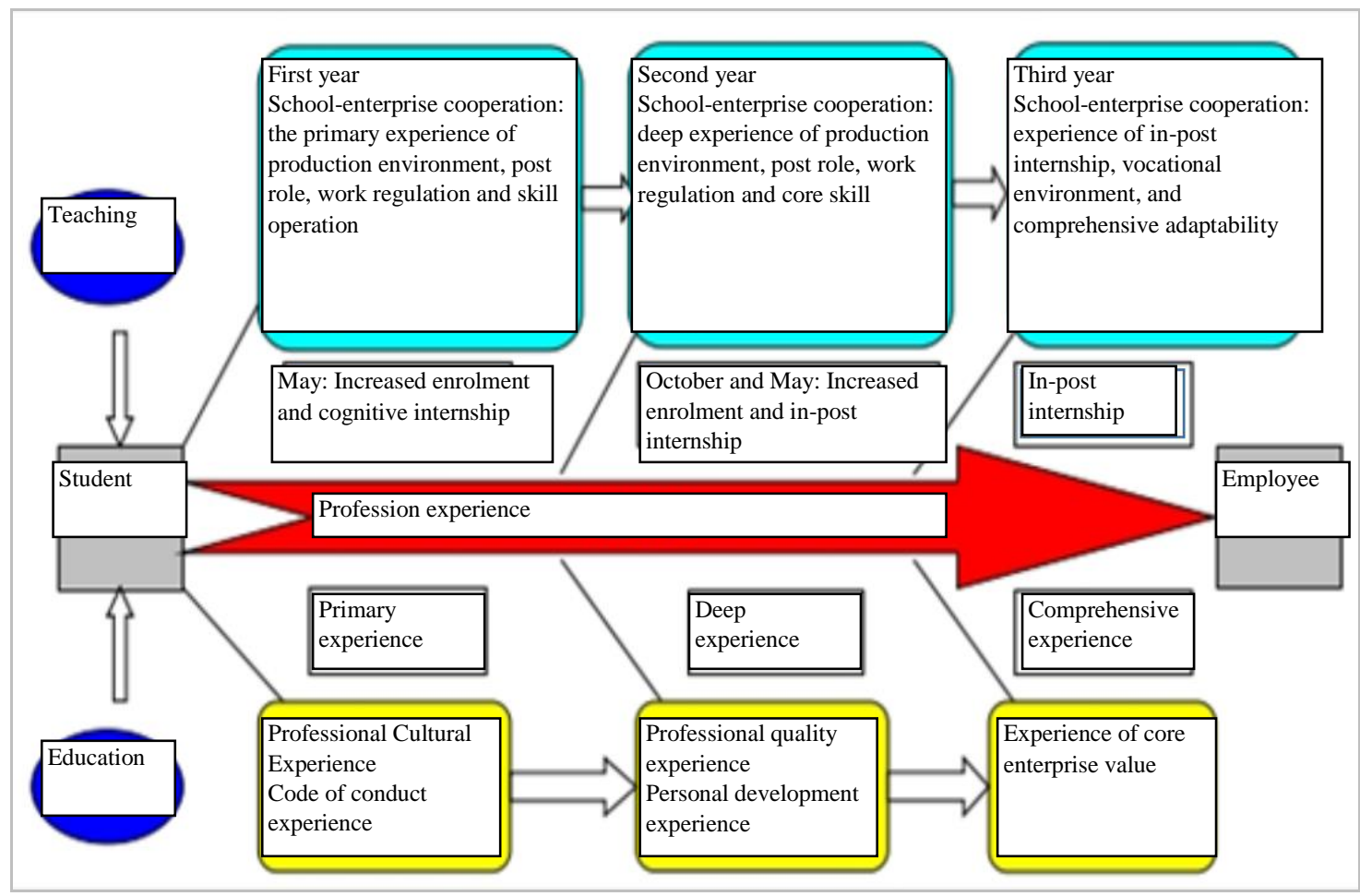

Figure 1 Talent training mode of "school-enterprise-industry co-cooperation, increased enrolment and fade-out".

4. THE CONSTRUCTION CONTENT OF THE TALENT TRAINING MODE OF "SCHOOLENTERPRISE-INDUSTRY COCOOPERATION, INCREASED ENROLLMENT AND FADE-OUT"

\subsection{Giving Full Play to the Superior}

Resources of the "Master Studio" Linking with the Industries and Enterprises, Giving Play to the Role of the Joint Education Between Schools and Enterprises, and Constructing the Education Concept of "Schoolenterprise-industry Co-cooperation, Increased Enrollment and Fade-out" to Improve the Comprehensive Competitiveness of Students and Meet the Multi-level Demands of Enterprises for Talents

It is necessary to give full play to the advantages of master studio connecting with enterprise and industry, carry out the deep cooperation with the local leading catering enterprises, such as Guilin Chunji Drink Industry Co. Ltd, Guilin Gouweiwang Catering Co., Ltd, Nanning Haoyouyuan banquet restaurant, Guangxi Liyuan Villa, and Guilin Catering and Cooking Association, establish the "Steering Committee of School-Enterprise-Industry Co-cooperation Construction", and jointly discuss professional construction and development together. Also, it is required to standardize the content, form and operation of joint construction and continue to conduct in-depth cooperation. ("Figure 2") 

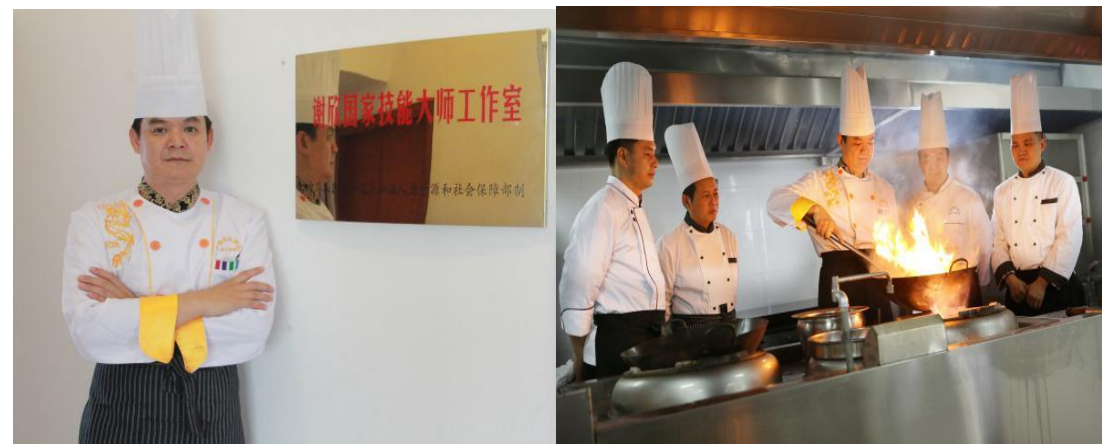

Figure 2 National Skilled Master Studio (Xiexin).

It is suggested to establish a national first-class teaching and training platform, and build a number of characteristic demonstration training bases for cuisine specialty with financial support from the central government and the autonomous region ("Table 1"), laying a solid foundation for the development of practical teaching.

Table 1. List of cuisine training bases in school

\begin{tabular}{|l|l|l|l|}
\hline $\begin{array}{l}\text { Serial } \\
\text { Number }\end{array}$ & Name of the training base & Level & $\begin{array}{l}\text { Fund } \\
\text { thousand } \\
\text { yuan) }\end{array}$ \\
\hline 1 & $\begin{array}{l}\text { National high-skilled personnel training base (three sub-bases } \\
\text { of Chinese cooking, Chinese and western pastry, and hotel } \\
\text { service and management have been built) }\end{array}$ & Central financial support & 500 \\
\hline 2 & $\begin{array}{l}\text { autonomous regional western cooking training base of } \\
6 \mathrm{~F}, \text { Fengqingyuan) }\end{array}$ & Central financial support & 500 \\
\hline 3 & $\begin{array}{l}\text { The autonomous regional demonstration characteristic } \\
\text { specialty of cooking technology and the practical training base }\end{array}$ & $\begin{array}{l}\text { Financial support from } \\
\text { autonomous region }\end{array}$ & 500 \\
\hline 4 & $\begin{array}{l}\text { Autonomous region-level demonstration specialty of food } \\
\text { processing and training base }\end{array}$ & $\begin{array}{l}\text { Financial support from } \\
\text { autonomous region }\end{array}$ & 500 \\
\hline 5 & $\begin{array}{l}\text { Autonomous region-level high-star hotel operation and } \\
\text { management demonstration specialty and training base }\end{array}$ & $\begin{array}{l}\text { Financial support from } \\
\text { autonomous region }\end{array}$ & 500 \\
\hline
\end{tabular}

National Skilled Master Studio (Xie Xin) is supported by the central finance. Liu Yangming Studio, an autonomous regional skilled master, Liang Guanqiang Studio, an autonomous regional skilled master, and $\mathrm{He}$ Yanjun Studio, an autonomous regional skilled master, have received financial support from the autonomous region. The teaching and training platform has the functions of teaching, scientific research, training, vocational skill appraisal, etc., meeting the needs of the integrated teaching reform of "teaching, learning, doing, training and evaluation", allowing students to experience the professional environment and training situation, and promoting the practical training platform of cuisine specialty to a new level. The training base has become the first "registered training and recognition base of Chinese cooking masters and masters of Zhuang Autonomous Region in Guangxi" identified by the Chinese Cuisine Association in Guangxi. At the same time, the education department of the autonomous region has identified the cooking training base of Guangxi Business School as "the cooking skills competition training base of Zhuang Autonomous Region" and allocated 500,000 yuan to support the construction. And Guangxi Cuisine Catering Industry Association and the culinary specialty of Guangxi Business School build "Guangxi Cuisine Base".

It is required to carry out multi-party cooperation to run schools and the implementation of the talent training mode of "school-enterpriseindustry, and increase enrolment and fade-out". The school cooperates with many enterprises to carry out the in-post internship. According to the "seasonal" labor time of catering enterprises, on May Day and National Day, it timely arranges students to the enterprise for a month-long training, so as to meet the demand of temporary work, integrate the professional theory learning in practice in time, enable students to have good professional knowledge, skills and actual combat experience before the post-practice, be familiar with enterprise culture, shorten the distance changing from student to professional person. ("Figure 3") 


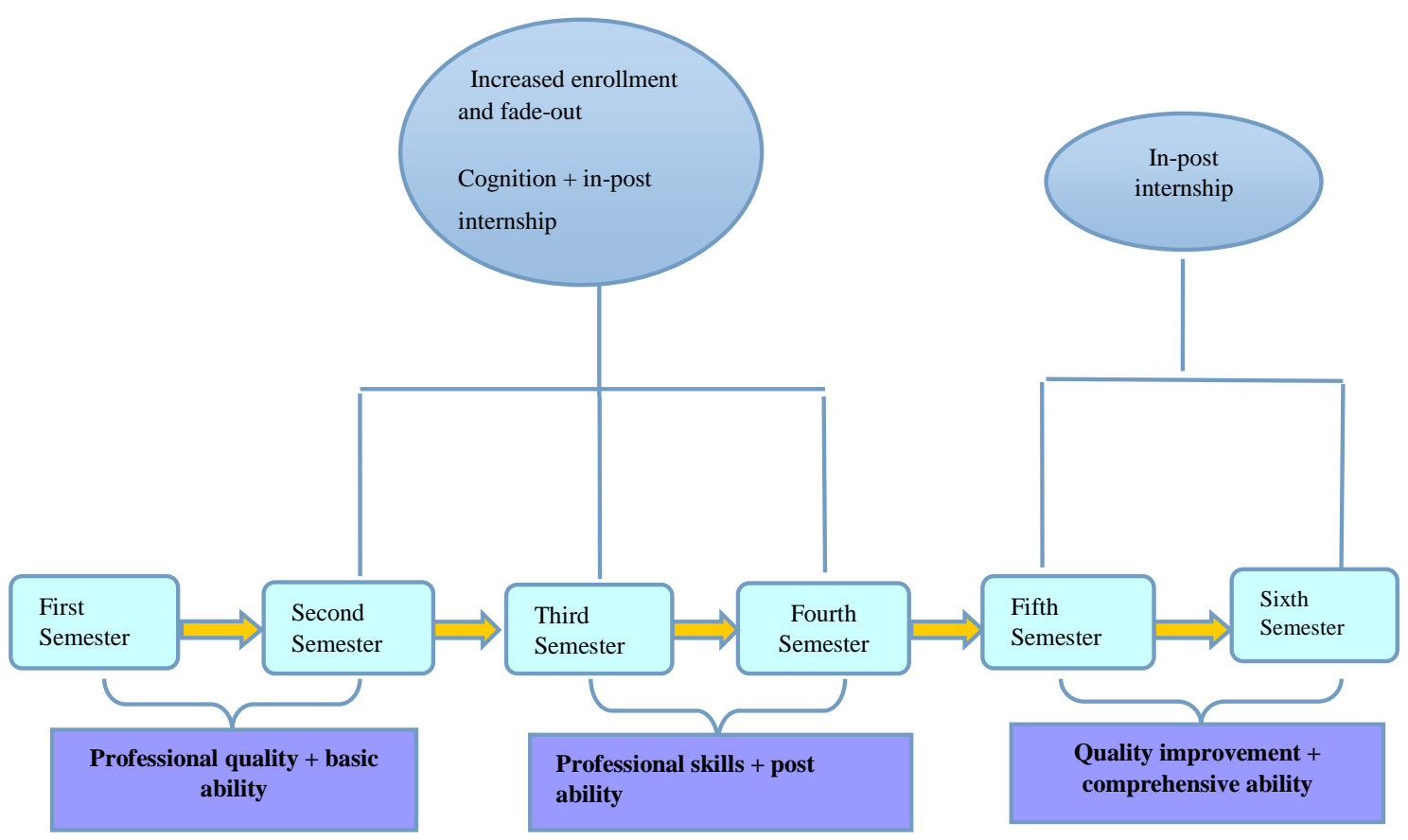

Figure 3 In-post internship cultivation diagram of "increased enrolment and fade-out".

Through the "Master Studio" platform, it is required to integrate advanced, mature and applicable professional standards, professional courses, teaching materials system and digital teaching resources inside and outside the region, and connect with Chinese high-quality cooperative enterprises to improve the level of professional construction. Also, it is necessary to carry out the training of "intermediate-senior", "secondary vocational-higher vocational", and "secondary vocational-undergraduate" talents, so as to realize the "through train" of academic qualifications and vocational qualifications, and improve the social competitiveness of students.

\subsection{Building an "Integrated" Curriculum} System of "School-enterprise-industry Docking", Achieving the Education Goal of "Three Upgradings", Improving Students' Comprehensive Vocational Ability, and Achieving the Accurate Docking of Talents and Enterprise Positions

It is suggested to improve the talent training program to ensure in-post and on-post internship. In the formulation of talent training program, the teaching links of in-post and on-post internship should be defined. The curriculum setting should be optimized, so as to distribute the core courses of the integrated major to each semester of students' learning stage. It is necessary to further reform the setting of the extended course, so that the extended course can dock with local characteristics and catering culture.

It aims to connect the curriculum setting with the needs of enterprises, the curriculum content with professional standards, and the curriculum teaching with the production process. A more perfect curriculum system for cuisine specialty will be formed, and the educational goal of "three upgrades" can be achieved, namely, the improvement of "professional quality + basic ability", "professional skills + post ability", and "quality + comprehensive ability" (see "Figure 4"). 


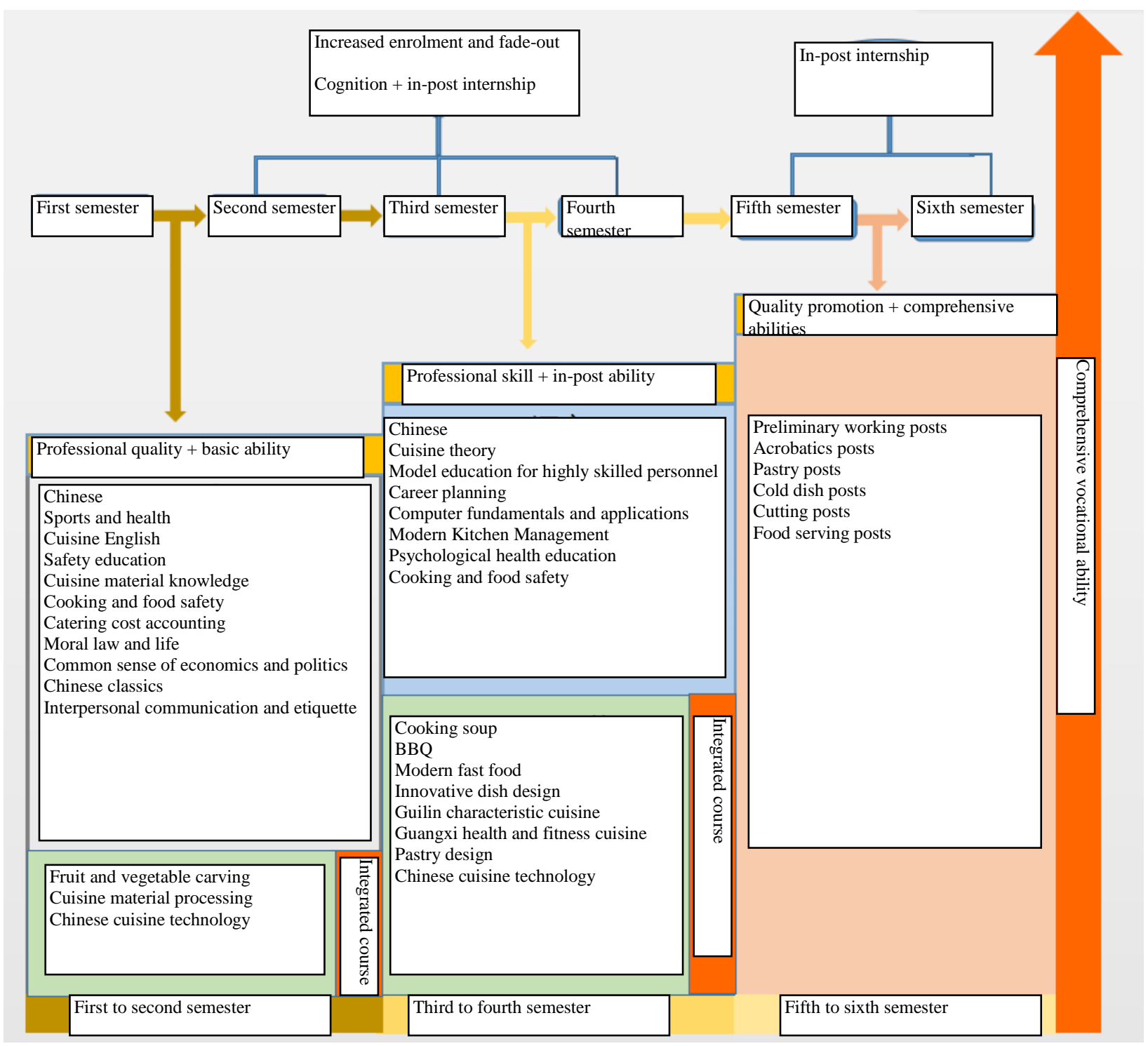

Figure 4 Schematic diagram of the curriculum system.

It is required to scientifically set up curriculum modules, reasonably distribute public basic courses, professional courses, and extended courses, and "integrated" courses run through each academic year, so that students can improve their skills and professional qualities simultaneously. Introducing project teaching into the classroom make practical teaching and theoretical teaching organically integrate, which not only enables students to master the necessary operating skills and theoretical knowledge, but also enables students to consciously integrate the theory and practice they have learned, and can also train the entrepreneurial ability and innovation ability of students.

It is required to carry out the reform of the integrated teaching model, promote the construction of the integrated teaching model, and improve the quality of teaching. Under the guidance of skilled masters and vocational education experts, it is necessary to carry out integrated curriculum design, integrated teaching design and establish a multi-integrated evaluation system in teaching. The work task is transformed from the work field $\rightarrow$ the action field $\rightarrow$ the learning field $\rightarrow$ the learning situation, and finally, the teaching documents such as the teaching plan, the syllabus, the course content, the school-based textbooks and so on are formed with the work process as the orientation [6]. In the teaching activities, teachers focus on the "integrated" teaching process and guide students to start with ideas on how to "learn", so that students can "learn well" instead of "how to learn". In the process of 
teaching, teachers mainly ask questions, give feedback and make comments.

It is suggested to set up extended courses according to local conditions, integrate local catering culture into teaching, and connect with the culture of ASEAN catering enterprises. At the same time, it is required to actively carry out the cultural activities of "high-quality culture going into the campus, corporate culture going into the professional culture and professional culture going into the classroom" to create a professional culture atmosphere [7].

\subsection{Integrating Multiple Resources, Implementing "One County and One Brand", Building a Tripartite Interest Community Among Schools, Enterprises and Industries, and Promoting In-depth Cooperation Between Schools and Enterprises}

Relying on the master studio, it is suggested to integrate various resources, carry out the project of "one county and one brand" for the industry and enterprises, establish the enterprise brand image, improve the connotation of the enterprise brand, and accelerate the better development of the enterprise. The project "one county and one brand" is a cooperation project jointly carried out by Guangxi Business School and Cuisine Association, so as to set up the enterprise brand image, improve enterprise brand connotation, and promote the better and faster development of enterprises. On the five principles of education first, win-win cooperation, seeking truth from facts, service and sustainable development, the comprehensive strategic partnership can be established. The implementation of the project of "one county and one brand" is based on the principle of school serving the enterprise. The school not only provides high-skilled talents for the enterprise, but also uses the "master" resources to train the employees, innovate the technology, improve the management and build the brand for the enterprise. This cooperation mode on technology and service has had a positive impact on the catering industry in Guangxi, especially in the county catering enterprises, and has not only contributed strength to the development of the local catering industry, but also contributed wisdom more importantly.("Figure $5 ")$

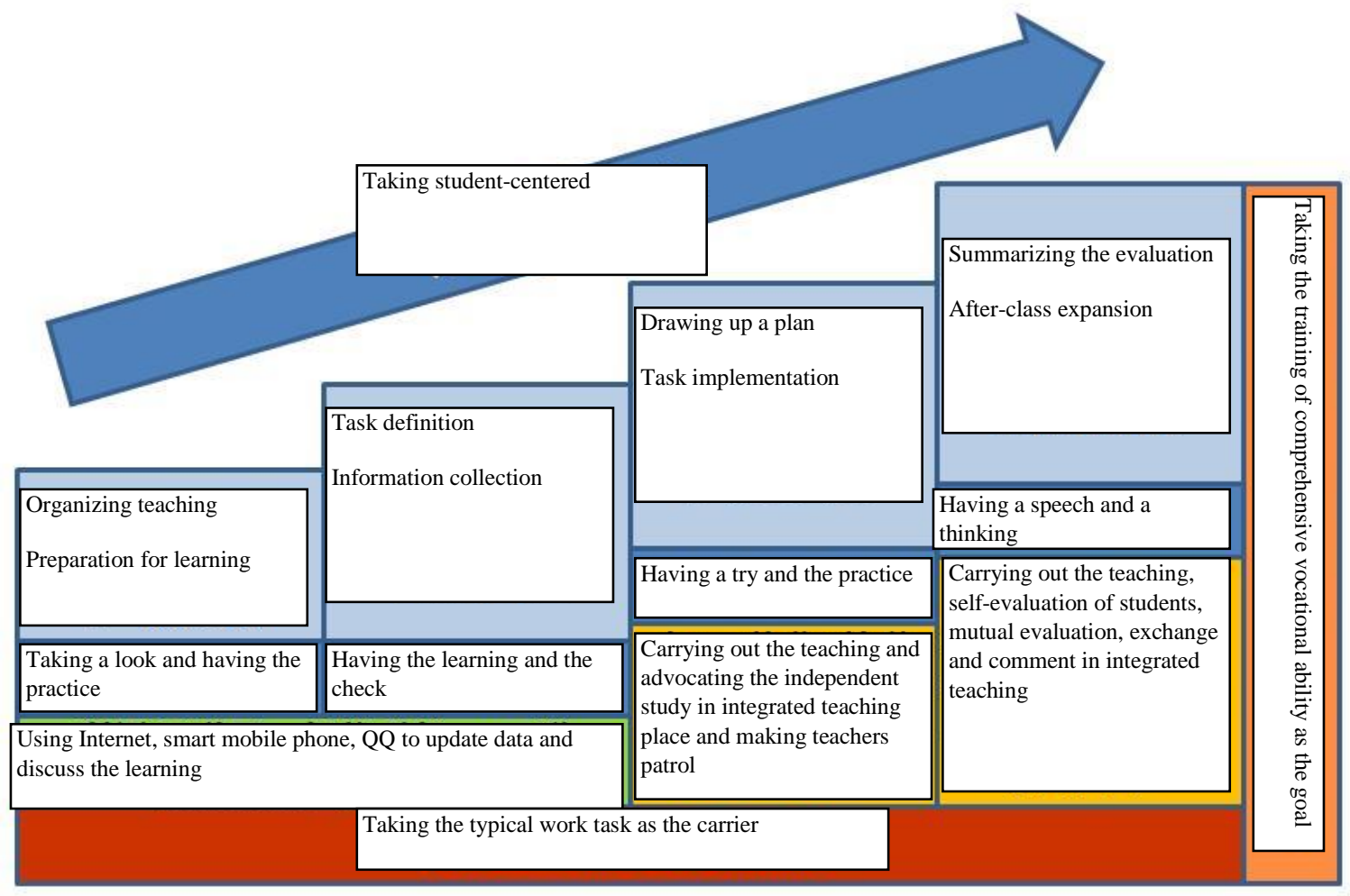

Figure 5 "Integrated" teaching flow chart.

Based on the project "one county and one brand", it is required to establish the brand image of the school, improve the brand connotation of the school, and enhance the social service ability of the 
school. With the school-enterprise-industry cooperation in running schools as the mechanism, the interests community of the school-enterpriseindustry mutual benefit and multiplicity of interests will be constructed to promote the in-depth cooperation among the schools, enterprises and industries.

It is better to develop a series of teaching materials and teaching resource databases with local, industrial and vocational characteristics. In recent years, the school has developed 8 books of Chinese cooking teaching materials and 11 books of school-based teaching materials. The school has invested more than 200,000 yuan to set up a shared teaching resource bank, which includes curriculum standards, teaching plans, practice bank, test bank, teaching plans, courseware, micro lessons, classroom records and other digital teaching materials. It is necessary to further standardize the construction of Chinese cuisine major, provide teaching resources for teachers of Chinese cuisine major, improve their ability to develop curriculum resources, and provide teaching resources for students' independent study.
It is suggested to strengthen the construction of teachers and realize the multi-dimensional flow of talents. At the same time, the school has built an "integrated" high-quality teaching team with advanced education concept, strong practical ability, high teaching level and the full-time and part-time teachers. Also, this school has formulated training programs for professional leaders, backbone teachers and young teachers, and implemented the "famous teacher project" and "integrated famous teacher project". It is suggested to give full play to the role of skilled master studios and industry associations, and improve the teaching level of teachers by inviting vocational education experts, Chinese cooking masters in the catering industry and skilled craftsmen of enterprises to have classes and arranging teachers to go out for further study. At the same time, national culinary masters and highly skilled teachers are invited to participate in the operation and management of enterprises, and they are employed as enterprise consultants to provide suggestions for the development of enterprises, so as to realize the multi-dimensional flow of talents and greatly expand the path for enterprises to participate in education. ("Figure 6")

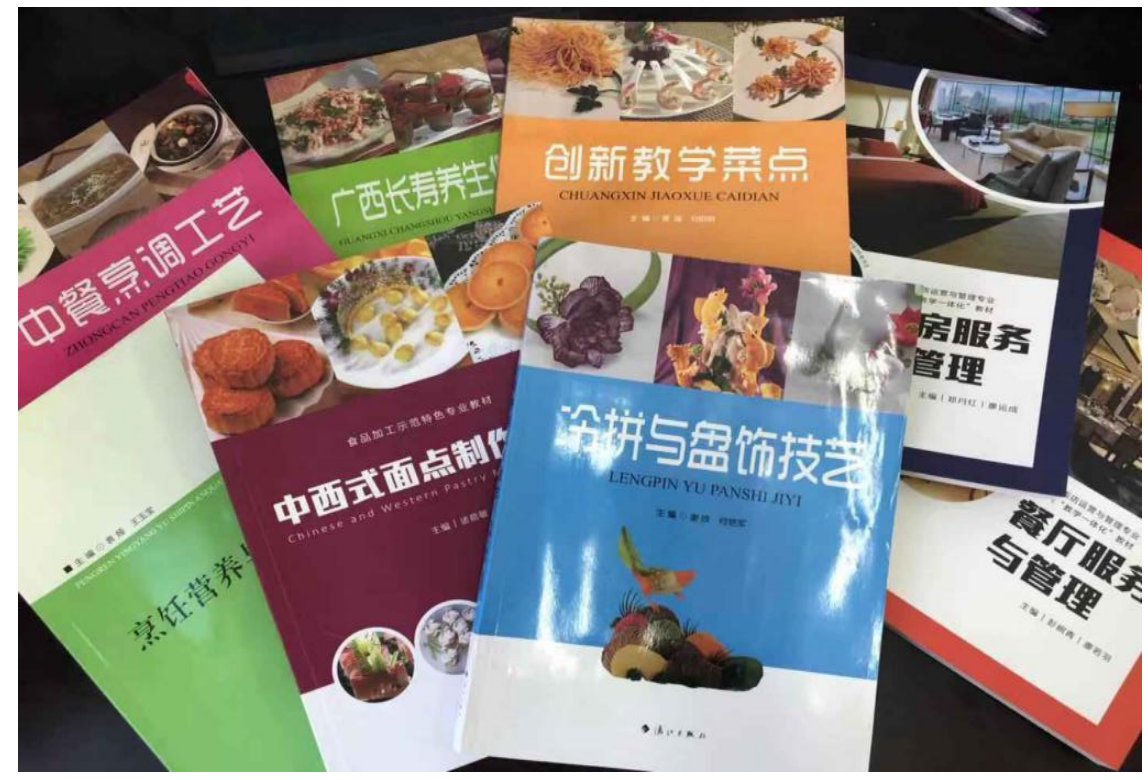

Figure 6 Part of textbooks compiled and published by school teachers.

\section{CONCLUSION}

In the course of the exploration and practice of the cultivation mode of cuisine specialty, according to the characteristics of cuisine specialty and the existing teaching problems, this paper puts forward a set of new talent cultivation system in the aspects of talent cultivation program, talent cultivation mode and curriculum system construction. Theoretical and practical innovations have been realized, and important achievements have been made in many aspects. 


\section{AUTHORS' CONTRIBUTIONS}

$\mathrm{Xin} \mathrm{Xie}$ is responsible the overall design of the article, and the completion of main work. Guanqiang Liang contributed to the design of frame structure and the verification of main data parameters are introduced in this paper. And Biyue Long is responsible for the preparation work and editing and contacting publishing paper.

\section{REFERENCES}

[1] Liu Yujuan. A Brief Talk on Integrated Teaching in the New Curriculum Reform, China Education Innovation Herald, 2013-124. (in Chinese)

[2] Yu Shibin, Deng Yunian, Pan Weirong. Research on the construction of "Integrated" teaching curriculum model — The results of the integrated teaching reform of automobile maintenance specialty, Chinese Vocational and Technical Education, 2007-11-9. (in Chinese)

[3] Qiu Jinlin. Research on curriculum development and resource sharing of E-skills and Training course, Higher Education Forum, 2015-12-6. (in Chinese)

Ju Chunfei, Zhao Jinguo, Yang Hongcai. Exploration and Practice of Modern Apprenticeship - Taking the Mechatronics Technology Major of Xijing University as an example, "Journal of Higher Education", 2016-11-18. (in Chinese)

[4] Gu Nengping. A Preliminary Study on the "Four-Three-Three" Talent Cultivation Approaches of the Modern Apprenticeship System in Higher Vocational Education Taking Tea Cultivation and Tea Processing as an Example, Higher Education Forum, 201812-8. (in Chinese)

[5] Zhu Jiaping, Analysis on the "Integrated" Talent Training Model of Secondary Vocational Education [J]. Chinese Vocational and Technical Education, 2018, 34, 91-96. (in Chinese)

[6] Gao Zhigang, Guilds in Schools, Famous Store Orders, Corporate Classrooms, Project Management - Exploration and Practice of the Training Model of Secondary Vocational Culinary Professionals $[\mathrm{J}]$. Chinese Vocational and Technical Education, 2015, 31, 69-74. (in Chinese)

[7] Chen Yan, Preliminary Study on the Training Model of "Order Type" Catering Management Talents [J]. Ability and Wisdom, 2017. 3, 217. (in Chinese) 